\begin{tabular}{|c|c|c|c|}
\hline \multirow[t]{2}{*}{ Species } & \multirow[t]{2}{*}{$\begin{array}{l}\text { No. in Bahan } \\
\text { (per cent) }\end{array}$} & \multicolumn{2}{|c|}{$\begin{array}{l}\text { Mean fleas/rat of } 229 \\
\text { examined in August } \\
\text { from Rangoon }\end{array}$} \\
\hline & & $\begin{array}{c}\text { Xenopsyl'a } \\
\text { astia }\end{array}$ & $\begin{array}{c}\text { Xenopsylla } \\
\text { cheopis }\end{array}$ \\
\hline $\begin{array}{l}\text { Bandicota bengalensis } \\
\text { (Gray and Hardwicke) } \\
\text { Rattus norvegicus (Berk) } \\
\text { Rattus rattus (Linn) } \\
\text { Rattus concolor (Blythe) } \\
\text { Mus musculus (Linn) } \\
\text { Suncus caeruleus (Kerr) } \\
\text { (Insectivora) }\end{array}$ & $\begin{array}{r}29 \\
0 \\
13 \\
45 \\
8 \\
4\end{array}$ & $\begin{array}{l}1 \cdot 5 \\
0 \cdot 5 \\
0 \cdot 1 \\
0 \cdot 2 \\
0 \\
0 \cdot 3\end{array}$ & $\begin{array}{c}0 \cdot 2 \\
0 \cdot 3 \\
0 \cdot 1 \\
0 \cdot 3 \\
1 \text { flea only } \\
0.3\end{array}$ \\
\hline
\end{tabular}

Only three rats were found infected with plague out of a total of 1,261 examined from the whole of Rangoon. All these were from Bahan, two being Rattus rattus and one Bandicota bengalensis.

In three cases where human plague deaths occurred, investigation produced a report of "white-bellied rats" dropping dead from the roof, a description which could only apply to Rattus rattus. The pecies in questi $r$.

No. 1 Pest Destruction Advisory Unit,

J. L. HARRISON.

R.A.S.C.,

Feb. 12.

${ }^{1}$ Barnett, Nature, 157, 105 (1946).

Apparatus for Measuring Mean Cell-Diameters in Blood Film

THE instrument $X$ described earlier ${ }^{1}$ is calibrated in relation to the use of the second red ring of the haloes. At the end it is noted that anisocytic spread of the spectra could so blur this band as to vitiate method.

The answer to this difficulty was kindly sent to me by Dr. Adrianus Pijper, pioneer of the halometer method, who devised the Zeiss-Pijper blood cell tester. Those familiar with that instrument will be aware that not only is it fitted to compare two blood-smears, a great advance in reliability over the single-smear method, but also it is calibrated to make use of the yellow ring. Since this ring is central to the spectra, it is naturally the narrowest, and is not spread by anisocytosis. The discrepancies involved can be judged from the fact that a factor related to the rotundity of red cells was omitted from the equation used as a basis of calibration, and yet results were good.

$\mathrm{I}$ am indebted to Mr. G. Rogers, of Cambridge, for pointing out that since blood cells are not square, but round, the equation should read $\sin \theta=1 \cdot 22 \mathrm{~N} / \mathrm{M}$

where $\theta$ is the angle of separation of the haloes, $N$ the order of ring used, and $l$ the wave-length of the ring.

It was noted that the wave-length which made the calibration coincide with that of the instruments previously used was somewhat short for the outer border of the red band, but there is a considerable surplus discrepancy which can only be accounted for by the spread of the red band.

The use of inferior practices is undesirable, and I am most grateful to Dr. Pijper for his criticism. I regret that I have not the flgures to hand for the preparation of a table according to these principles. Whereas the table in my original communication suits the technique in use with the Eve halometer, familiar to so many, it is recommended that a fresh table be prepared according to the revised equation above, using a wave-length in the yellow.

No. 1 Field Bacteriological Unit,
U.N.R.R.A. Mission, Yugoslavia.

HARRY HOGBEN. Nov. 25 .

${ }^{1}$ Nature, 155, 576 (1945).

\section{Histological Technique for Endocrine Glands of Birds}

WE have been making histological preparations of all the recognized endocrine organs (including thymus) of the common wild duck (Anas platyrhyncha $p$.L.) for some time. In the course of this work we gained some experience in the use of a number of methods of histological procedure as applied to these tissues, and it seems to us that our findings may be of value to others.

Whe may be of value to others. the sections of the adrenal glands showed a very strong tendency to the sections of the adrenal gassage through the reagents used for debecome detached during passage verough this difficulty satisfactorily hydration. We were unable to overcome this dificulty satisfactorily until we used a 1 per cent solution of commercial powdered albumen (Gurrs) as adhesive medium. This adhesive solution had to be made bottle. Phenol may possibly be a more effective preservative. This solution was spread on the slide in the manner of making a blood film and the slide dried in an incubator. We found this solution far superior to the usual egg-white glycerin mixture ${ }^{1}$ and also Hewer's potassium bichromate. gelatine solution ${ }^{2}$ We found the 1 per cent solution sufficiently concentrated to ensure flrm adhesion of the sections, withstronger solutions.

We tried out a number of differential stains for the anterior lobe of the pituitary (of the common wild duck), namely, Mann's methylblue eosin, long method ${ }^{3}$ Biggart's eosin yellow and pyrrol bluet, first two did not give a sharp differentiation of cell types in our hands. Dawson and Friedgood's method was satisfactory, but much more time-consuming than the modification of Crooke and Russell's acid fuchsin and Mallory's aniline blue mixture ${ }^{s}$ to be described. The details of this method were given us by Dr. Keith C. Richardson, of the Department of Anatomy, University College, London, now published for the flrst time with his consent:

1. Fix the freshly dissected pituitary (or for birds, base of skull with pituitary in situ) in Zenker-formol (9 vol. Zenker, 1 vol. commercial formalin, neutralized to give an olive-green reaction with bromthymol blue) $8-12$ (to 24 ) hours. 2. Wash out in running water overnight (for undissected pituitaries, decalcify). 3. Dehydrate and imbed in paraffin wax. Toluol, carbon disulphide or cedarwood oil are suitable clearing agents. 4. Cut sections at $4 \mu$ or thinner, if possible. 5. Bring sections down to water, using iodine-alcohol to remove mercuric crystals. 6. Wash well with distilled water and stain one minute or longer in Altmann's aniline acid fuchsin (a saturated solution of acid fuchsin in aniline oil-water) (see techniques for staining mitochondria). The sections must be stained very strongly red. Heating the slide with a small amount of stain (flitered) over a spirit lamp until vapour comes off is recommended. 7 . Wash quickly in distilled water to remove surplus stain. Differentiate in a saturated solution of picric acid. The stain should come out fairly rapidly, and
the slide should be rinsed in water and examined from time to time under the microscope. Continue until the alpha cells are very strongly red and the rest are very light pink or even neutral in colour. 8. Wash well in distilled water to remove picric acid. 9 . Place in 1 per cent phosphomolybdic acid for one minute. 10. Rinse in distilled water. 11. Transfer to Mallory's aniline blue-orange $G$ (original formula: aniline blue, $0.5 \mathrm{gm}$.; orange $G, 2.0 \mathrm{gm}$; ; oxalic acid, $2.0 \mathrm{gm}$.;
distilled water, 100 c.c.). The sections are left in this until the basodistilled water, 100 c.c.). The sections are left in this until the basophils are a strong blue and the chromophobes light grey or very pale blue. The length of time will vary with the material and with the degree of differentiation of the red ( 35 minutes for duck's pituitary). The slide may be rinsed with distilled water and examined during edges of section; plunge in absolute alcohol until excess stain is removed; xylol, mount in Canada balsam.

Dr. Richardson has used this technique on a number of mammalian species with good results, and we can conflrm that it is equally effective for the avian as well as the frog's pituitary, acidophils being stained sharply orange-red and basophils being fairly satisfactorily differentiated from chromophobes. It seems probable that the revised method for the 'Quad' stain" recently published, which we have not yet had an opportunity of trying, may give even sharper differentiaorange $G$ mixture as opposed to the combined solution used by us. E. O. HöHN.

Department of Physiology,
Guy's Hospital Medical School, London, S.E.1. Jan. 17.

${ }^{1}$ Carleton, H. N., and Leach, E. A. G., "Histological Technique" (2nd ed., 1938), 74

2 Hewer, E.' E., "Text-Book of Histology for Medical Students" (1937), appendix, 347 .

${ }^{3}$ Carleton, H. N., and Leach, E. A. G., op. cit., 431.

"Gatenby, J. B., and Painter, T. S., "Microtomists' Vade-Mecum" (10th ed.), par. 909

${ }^{5}$ Dawson and Friedgood, Stain Tech., 13, 17-21.

${ }^{6}$ Gatenby, J. B., and Painter, T. S., op. cit., par. 909.

'Kornhauser, S. Y., Stain Tech., 20, 33-35.

\section{Maintenance of Heterozygosity in a Homothallic Species} of the Neurospora tetrasperma Type

IN the homothallic ascomycete Neurospora tetrasperma, two nuclei are normally included in each ascospore, one of mating type $A$ and one of mating type $a . N$. tetrasperma is therefore normally a dikaryon and heterozygous for the $A a$ factors. It is interesting to note that the inclusion of an $A$ and an $a$ nucleus in one ascospore leads to the maintenance of heterozygosity of other factors not on the same chromosome but segregating at the same time as the $A a$ factors. A factor segregates at the flrst meiotic division if there has been no crossingover between the factor and the centromere of the chromosome on which it is placed. If there has been such crossing-over the factor segregates at the second division. A factor placed about fifty cross-
over units from the centromere would be expected to show 100 per cent second division segregation, apart from the effect of double cross-overs.

If we suppose that the $A a$ factors segregate at the first division, a pair of factors $B b$, also segregating at the first division, will behave as plustrated in Fig. 1.

The resulting ascospores are heterozygous for $B b$ as well as for $A a$. Each ascus contains only one type of spore, either $A B, a b$ or $A b, a B$ and there should be equal numbers of asci with $A B, a b$ and $A b, a B$ spores.

If we suppose that the $A \alpha$ factors segregate at the second division, the behaviour of the factors $B b$, also segregating at the second division, is shown in Fig. 2. The diagram only takes into account the situation when $a$ factors passing into one nucleus after the first division are re-associated in the spores, since other associations are unlikely to ad to the formation of four normal bisexual spores.

In this case half the asci should contain spores of two types, namely, $A B, a b$ and $A b, a B$. The occurrence or non-occurrence of the two types of spores within an ascus affords a method of determining whether the two factors segregate mainly at the flrst or second division.

Recently, Dodge, Schmitt and Appel' have published an analysis of the results of a cross involving $D d$, for normal versus ascospore It was found that the $D d$ factors rarely segregate in the progeny, 